\title{
La indebida diligencia de la labor fiscal en las investigaciones por delitos de corrupción de funcionarios
}

\section{The improper diligence of the fiscal work in the investigations for crimes of corruption of officials}

\author{
Franklin Hoyos Huamán ${ }^{1}$, Roberto Guevara Aranda ${ }^{2}$
}

\section{RESUMEN}

La presente investigación tuvo como objetivo determinar de qué manera la indebida diligencia de la labor fiscal en las investigaciones por delitos de corrupción de funcionarios genera el archivo de las investigaciones en la Fiscalía Provincial Especializada en Delitos de Corrupción de Funcionarios de Chachapoyas, durante el periodo 20162017. La metodología utilizada en la investigación se orientó en analizar las disposiciones fiscales de archivo que fueron posteriormente revocadas, las cuales permitieron analizar los criterios utilizados por los fiscales provinciales y superiores en cada caso concreto. La población estuvo conformada por 18 carpetas fiscales $(100 \%)$ de las cuales se extrajo como muestra 10 carpetas fiscales (55.6\%). Para la recolección de datos se utilizó la observación directa no participante y el análisis de expedientes. Se usaron fichas de registro y estudio de casos, cuadro de resumen y cuadro comparativo. Se encontró un alto índice de denuncias archivadas, pues de un total de $139(100 \%)$ denuncias registradas, 115 (83\%) fueron archivadas durante la etapa de investigación preliminar. De las $115(100 \%)$ denuncias archivadas, solo 51 (44\%) han sido impugnadas mediante el recurso de elevación de actuados. De las 51 (100\%) denuncias impugnadas, 18 (35\%) han sido revocadas, es decir, 4 de cada 10 denuncias archivadas son revocadas. Finalmente, se concluyó que el archivo inadecuado de las denuncias es producto de la poca diligencia que tienen los señores fiscales para realizar una exhaustiva investigación de los delitos.

Palabras clave: Debida diligencia, investigación fiscal, archivo.

\section{ABSTRACT}

The objective of this investigation was to determine how the undue diligence of the prosecutorial work in the investigations for crimes of corruption of officials generates the file of the investigations in the Provincial Prosecutor's Office Specialized in Crimes of Corruption of Officials of Chachapoyas, during the period 2016 2017. The methodology used in the investigation was aimed at analyzing the archival tax provisions that were later revoked, which allowed the analysis of the criteria used by provincial and superior prosecutors in each specific case. The population consisted of 18 fiscal folders (100\%) of which 10 fiscal folders $(55.6 \%)$ were taken as a sample. Non-participant direct observation and file analysis were used for data collection. Record sheets and case studies, summary table and comparative table were used. A high rate of filed complaints was found, since out of a total of $139(100 \%)$ registered complaints, $115(83 \%)$ were filed during the preliminary investigation stage. Of the $115(100 \%)$ complaints filed, only $51(44 \%)$ have been challenged by means of the appeal to raise the proceedings. Of the $51(100 \%)$ contested complaints, $18(35 \%)$ have been revoked, that is, 4 out of every 10 filed complaints are revoked. Finally, it was concluded that the inadequate filing of the complaints is the result of the little diligence that the prosecutors have to carry out an exhaustive investigation of the crimes.

Keywords: Due diligence, tax investigation, file.

\footnotetext{
Abogado por la Universidad Nacional Toribio Rodríguez de Mendoza de Amazonas. Correo electrónico: frankhoyos17@gmail.com 2 Abogado, Mg. en Derecho Constitucional. Docente de la Facultad de Derecho y Ciencias Políticas de la Universidad Nacional Toribio Rodríguez de Mendoza de Amazonas. Correo electrónico: segundo.guevara@untrm.edu.pe
} 


\section{INTRODUCCIÓN}

El fenómeno de la corrupción ha sido una preocupación constante a nivel nacional como internacional, es por ello, que importantes instrumentos internacionales como la Convención Interamericana contra la Corrupción (CICC) del año 1996 y la Convención de las Naciones Unidas contra la Corrupción (CNUCC) del año 2003, establecieron recomendaciones que deben cumplir los Estados miembros, esto con el afán de prevenir, detectar, sancionar y erradicar la corrupción.

Al respecto, entendemos que la corrupción afecta a las instituciones del Estado, materializada en la labor de los funcionarios y la vida cotidiana de los ciudadanos; pues lejos de ser un fenómeno aislado que se circunscribe solo a las altas esferas del poder político o económico, es evidente su incidencia en la esfera social. Por lo tanto, su importancia no radica solo en los bienes que se desvían o en la cantidad de dinero que el Estado pierde, sino, sobre todo, en los derechos que vulnera y en las barreras que genera para el acceso a los servicios básicos de salud, educación, justicia, entre otros. En consecuencia, desde esta óptica, la corrupción implica un problema de derechos, tal como lo ha precisado la Defensoría del Pueblo (Informe Defensorial $N^{\circ} 168,2014$ ).

En definitiva, la corrupción es un problema transversal en el Estado peruano, que la ciudadanía percibe como uno de los principales defectos de las instituciones públicas, pues merma sus recursos y eficiencia. Según un informe de la Contraloría General de la República del 2015, la corrupción le cuesta al Estado aproximadamente 12600 millones de soles al año, monto que representaba un poco menos del 10\% del presupuesto nacional.

Frente a esta realidad, desde el destape de la corrupción en el año 2000 (gobierno de Alberto Fujimori), se han emprendido múltiples políticas anticorrupción enfocadas en prevenir, sancionar y erradicar la corrupción. Como resultado, se ha obtenido, que no se ha disminuido los índices de corrupción, más bien, éste se ha ido incrementado a razón de las denuncias de los ciudadanos; situación que ameritó la creación de la Fiscalía Especializada en Delitos de Corrupción de Funcionarios, con la finalidad de que profesionales especializados en la materia se avoquen a investigar exclusivamente estos casos a fin de obtener mejores resultados.

Desde tal perspectiva, si bien es cierto, ha incrementado las denuncias por corrupción en la Administración Pública; no obstante, son reducidos los procesos que concluyen imponiendo sanciones a los responsables, en su mayoría debido a una insuficiente actuación probatoria, es decir, la mayor parte de los procesos se archivan en la etapa de investigación.

Al respecto, la Defensoría del Pueblo (2014), precisa, que la tasa de archivo de denuncias investigadas bajo el NCPP es alta, no sólo a nivel general sino también en nuestro ámbito de estudio (delitos de corrupción de funcionarios). Y hay además señales claras para preocuparse por su proporción y suponer que existe un porcentaje importante de casos que se archivan cuando en realidad deberían formalizarse para continuar con la investigación, y en una etapa posterior, con más elementos de cargo, decidir si se acusa o se dicta su sobreseimiento (Informe defensorial $\mathrm{N}^{\circ} 168$, p. 21).

De lo citado, podemos colegir que el problema del fracaso de los procesos por corrupción de funcionarios se encuentra en la etapa de investigación preliminar, que está a cargo del Ministerio Público como titular de la acción penal; por lo que, al realizar un análisis de la situación de los casos en la Fiscalía Provincial Especializada en Delitos de Corrupción Funcionarios de Chachapoyas, se advirtió que el archivo de los procesos se debía a la falta de diligencia de los fiscales durante la investigación preliminar, entendiendo que ésta etapa es medular para llevar adelante un proceso.

Entonces, en la práctica se tiene que los señores fiscales especializados en delitos de corrupción de funcionarios de la provincia de Chachapoyas no estarían realizando su labor fiscal con la debida diligencia que se requiere para investigar dichos delitos, por lo cual el objetivo de la presente investigación será analizar si los fiscales de la citada provincia realizan una adecuada investigación e interpretación de los hechos delictivos, y cuáles son las deficiencias que se observan durante el desarrollo de la investigación de los delitos de corrupción de funcionarios.

\section{MATERIAL Y MÉTODOS}

El diseño de la presente investigación fue de carácter no experimental, de modo transeccional o transversal, tipo descriptivo-analítico. El ámbito de estudio se circunscribió a las carpetas fiscales con archivo revocado de la Fiscalía Provincial Especializada en Delitos de Corrupción de Funcionarios de Chachapoyas, del periodo 20162017. De una población de 18 carpetas fiscales $(100 \%)$ se ha tomado una muestra de 10 carpetas (55.6\%). El método que se usó fue el método lógico, deductivo, inductivo, analítico, interpretativo y estadístico. Las técnicas que se utilizaron para la recolección de datos fue la observación directa no participante y el análisis de expedientes. Y los instrumentos que se usaron para recolectar y procesar la información fueron las fichas de registro y estudio de casos, cuadro de resumen y cuadro comparativo. 


\section{RESULTADOS}

Tabla 1: Carpetas fiscales archivadas y formalizadas.

\begin{tabular}{|c|c|c|}
\hline \multicolumn{3}{|c|}{$\begin{array}{c}\text { Carpetas fiscales con archivo y con } \\
\text { formalización de la investigación }\end{array}$} \\
\hline Estado & Cantidad & Porcentaje \\
\hline Con archivo & 115 & $83 \%$ \\
\hline Con F.I.P. & 24 & $17 \%$ \\
\hline TOTAL & $\mathbf{1 3 9}$ & $\mathbf{1 0 0 \%}$ \\
\hline
\end{tabular}

Tabla 2: Carpetas fiscales con formalización de la investigación.

Carpetas Fiscales con Formalización de Investigación Preparatoria

\begin{tabular}{|l|c|c|}
\hline \multicolumn{1}{|c|}{ Estado } & Cantidad & Porcentaje \\
\hline Con F.I.P. & 11 & $8 \%$ \\
\hline Con Sobreseimiento & 6 & $4 \%$ \\
\hline Con Acusación & 4 & $3 \%$ \\
\hline Con Sentencia & 3 & $2 \%$ \\
\hline \multicolumn{1}{|c|}{ SUB-TOTAL } & $\mathbf{2 4}$ & $\mathbf{1 7 \%}$ \\
\hline
\end{tabular}

Tabla 3: Carpetas fiscales archivadas y elevadas a

la Fiscalía Superior Penal de Amazonas

Casos archivados y elevados a la FSP

\begin{tabular}{|c|c|c|}
\hline \multicolumn{1}{|c|}{ Estado } & Cantidad & Porcentaje \\
\hline Archivos impugnados & 51 & $44 \%$ \\
\hline Archivos no impugnados & 64 & $56 \%$ \\
\hline TOTAL & $\mathbf{1 1 5}$ & $\mathbf{1 0 0} \%$ \\
\hline
\end{tabular}

Tabla 4: Carpetas fiscales con archivo confirmado y con archivo revocado

\begin{tabular}{|l|c|c|}
\hline \multicolumn{3}{|c|}{ Casos con archivo confirmado y revocado } \\
\hline \multicolumn{1}{|c|}{ Estado } & Cantidad & Porcentaje \\
\hline Archivos confirmados & 29 & $57 \%$ \\
\hline En trámite & 4 & $8 \%$ \\
\hline Archivos revocados & 18 & $35 \%$ \\
\hline \multicolumn{1}{|c|}{ TOTAL } & $\mathbf{5 1}$ & $\mathbf{1 0 0 \%}$ \\
\hline
\end{tabular}

\section{DISCUSIÓN}

El fiscal, en cuanto tenga noticia del delito, realizará si correspondiere- las primeras Diligencias Preliminares o dispondrá que las realice la Policía Nacional, pero siempre bajo su conducción y control. De cualquier determinación que tome, tendrá que diseñar su estrategia de investigación. Para dicho efecto el fiscal tendrá que emitir una disposición de apertura de investigación preliminar, y en el mismo disponer la realización de las diligencias requeridas, señalando el plazo de acuerdo a la complejidad o no de la misma (Rosas, 2009).

Recordemos que las diligencias preliminares tienen por objeto establecer si el hecho denunciado realmente ocurrió, calificar si el hecho denunciado es amparable penalmente, individualizar a los presuntos responsables del hecho y acopiar indicios reveladores de la existencia del delito.

Al respecto, es necesario mencionar que las disposiciones de archivo, de conformidad con el artículo $334^{\circ}$ del Código Procesal Penal, recae durante la investigación preliminar por tres supuestos: i) si el hecho denunciado no constituye delito, ii) si el hecho denunciado no es justiciable penalmente, o iii) si se presentan causas de extinción previstas en la ley.

El fiscal puede archivar el caso al calificar la denuncia o después de haber realizado o dispuesto realizar diligencias preliminares, siendo que en el primer caso se produce un archivo denominado archivo liminar, porque se emite sin que se haya realizado acto de investigación alguno, y en el último caso se emite una disposición denominada archivo preliminar, ya que es emitida luego de haberse realizado diligencias preliminares de investigación (Arana, 2014,p. 267).

Contra la decisión que dispone el archivo de la investigación, el denunciante o agraviado que no estuviese de acuerdo con tal decisión, requerirá al fiscal, en el plazo de cinco días, eleve las actuaciones al fiscal superior, quien en igual tiempo se pronunciará.

Una vez elevados los actuados, el fiscal superior podrá finalmente: (i) Ordenar la formalización de la investigación preparatoria, en cuyo supuesto, por el principio de jerarquía que rige en el Ministerio Público, el fiscal provincial tendrá que cumplir la disposición de su superior; (ii) Ratificar el criterio del fiscal provincial, en este supuesto se constituye cosa decidida y la investigación se archiva de forma definitiva; y, (iii) Ordenar la realización de diligencias adicionales al fiscal provincial a fin de emitir una nueva disposición (San Martín, 2015).

En suma, si el fiscal superior opta por declarar fundado el pedido de elevación de actuados y como consecuencia revocar o declarar nula la disposición fiscal de archivo, es evidente que durante la investigación preliminar el fiscal a cargo de la investigación no ha actuado de manera diligente y eficiente.

Cabe resaltar, que la obligación del Ministerio 
Público radica en la averiguación, obtención y calificación jurídica de los elementos que ayuden a probar la comisión del delito. Sin embargo, en la práctica dicha potestad de persecución penal se ejerce de manera débil e insuficiente, que con el tiempo genera consecuencias políticas, económicas y sociales en la lucha contra la corrupción, toda vez que los procesos en su mayoría se ven afectados por archivos inadecuados que provocan una sensación de injusticia e impunidad en la población.

Contar con el total de denuncias por delitos de corrupción de funcionarios en la Fiscalía Provincial Especializada en Delitos de Corrupción de Funcionarios de Chachapoyas, durante el periodo 2016-2017, nos ha permitido ahondar el tema de investigación, pues de ahí se pudo advertir si los fiscales a cargo de las investigaciones cumplieron prolijamente con sus labores, toda vez que no podría considerarse que realizan un trabajo diligente si la mayoría de las investigaciones son archivadas, y de ellas un gran porcentaje son revocadas.

Según datos proporcionados por el Ministerio Público, tenemos que en el periodo 2016 - 2017 se registraron un total de 139 denuncias por delitos de corrupción de funcionarios. De ellas, 115 denuncias que representan el $83 \%$ han sido archivadas, y solo 24 denuncias que representan el $17 \%$ se ha dispuesto formalizar y continuar con la investigación preparatoria; advirtiéndose por lo tanto un alto índice de archivo de denuncias (Tabla 1).

Dichos resultados concuerdan con las estadísticas obtenidas por la Defensoría del Pueblo en su Informe Defensorial $\mathrm{N}^{\circ} 168$ (2014), en donde indica que, según el Informe de la Comisión Técnica de Implementación del Nuevo Código Procesal Penal, el $62 \%$ de todas las denuncias penales de los 11 distritos fiscales fueron archivadas en los cuatro primeros años de implementación de la reforma. En el ámbito de las Fiscalías Especializadas en Delitos de Corrupción de Funcionarios el índice es menor: archivaron 3475 denuncias, lo que equivale al 41\% de las que recibieron en el mismo año. Si nos centramos en los delitos más frecuentes que éstas conocen (peculado y colusión), la tasa promedio de archivo es del 50\%, es decir, la mitad de denuncias termina en la etapa preliminar.

Asimismo, de las 24 denuncias en que el fiscal ha dispuesto formalizar investigación preparatoria, se observó que 6 de ellas (4\%) han sido sobreseídas en la etapa intermedia de la investigación, 4 (3\%) denuncias se encuentran con requerimiento de acusación, y solo 3 denuncias que representan el 2\% han pasado a la etapa de juicio oral concluyendo con una sentencia (Tabla 2).

De otra parte, del total de 115 denuncias que han sido archivadas, solo 51 denuncias que representan el $44 \%$ han sido impugnadas mediante el recurso de elevación de actuados, mientras que $64(56 \%)$ de ellas no han sido impugnadas, por lo que se han archivado definitivamente (Tabla 3).

Ahora bien, del total de 51 denuncias que han sido impugnadas, 29 (57\%) han sido confirmadas sus archivos, 4 (8\%) aún se encuentran en calificación y $18(35 \%)$ de ellas han sido revocadas (Tabla 4). Es decir, de cada 10 denuncias archivadas e impugnadas 4 son revocadas por la fiscalía superior, por advertirse un archivo inadecuado en el actuar de los fiscales de la Fiscalía Provincial Especializada en Delitos de Corrupción de Funcionarios de Chachapoyas.

En consecuencia, ha quedado evidenciado que el porcentaje de archivos de denuncias por delitos de corrupción de funcionarios es significativamente alto. En efecto, dichos resultados no responden a las exigencias de la sociedad, más bien resultan ser un fracaso de las políticas anticorrupción, pues no se trata de solo incentivar a los ciudadanos a denunciar los actos de corrupción, sino que las instituciones involucradas deben contar con personal idóneo, eficiente, probo, imparcial y capaces de asumir con solvencia la difícil misión de luchar contra la corrupción.

Cabe anotar, que el problema no es el archivo en sí mismo, pues ello está previsto en el Código Procesal Penal (art. 334 ${ }^{\circ}$, inc. 1), sino el archivo inadecuado de las denuncias.

La corrupción es un flagelo que ha socavado las instituciones públicas del Estado, atentando contra la sociedad, el orden moral, la justicia y desarrollo integral de los pueblos, situación que ha propiciado que el Estado implemente políticas de lucha contra la corrupción, que muy poco han podido contribuir en prevenirla, sancionarla y erradicarla, toda vez, que demanda de un compromiso uniforme entre las diferentes instituciones públicas (Ministerio Público, Poder Judicial, Policía Nacional, Contraloría General, Procuradurías Anticorrupción) y la colectividad social en general.

De los casos analizados en la presente investigación, se ha advertido que los fiscales no han cumplido prolijamente con su labor, es decir, no fueron diligentes para investigar, calificar los hechos denunciados y motivar sus disposiciones, generando con ello archivos inadecuados. impunidad al impedir que determinadas causas sigan el trámite procesal regular que puede conducirlas a

Al respecto, la Defensoría del Pueblo al realizar un estudio sobre "El archivo fiscal de denuncias por peculado y colusión en los distritos fiscales de Lima, Ancash, Ayacucho y Junín", con mucha razón 
sostiene que el archivo inadecuado genera un alto costo para el sistema, pues genera el riesgo de impunidad al impedir que determinadas causas sigan el trámite procesal regular que puede conducirlas a un juicio oral y a una condena para los responsables de actos de corrupción. Además, precisa que, a más archivos inadecuados o indebidos, menos denuncias que se investigan, menos sentencias, menos condenas y más impunidad (Informe defensorial $\mathrm{N}^{\circ}$ 168, 2014, p. 17).

En esta línea de ideas, podemos decir que el solo hecho de archivar un proceso de manera inadecuada genera no solo un gasto innecesario al sistema, sino que trae consigo también una sensación de impunidad que alimenta la desconfianza en la justicia, conforme se corrobora en la VIII Encuesta Nacional sobre Percepción de la Corrupción en el Perú, al establecer que el $86 \%$ de la población percibe que los resultados de las denuncias por corrupción son poco o nada efectivas (Proética, 2013).

Los archivos inadecuados son el resultado de una investigación con deficiencias marcadas, que se han identificado, evaluado y medido. Son varias las razones que permiten calificar a un archivo como tal: desidia para obtener información y realizar el peritaje necesario, falta de minuciosidad en el análisis de la información obtenida, inadecuada gestión de la obtención de la información, inadecuada valoración de la relación funcional de los implicados, falta de estrategia en la toma de declaraciones, falta de reprogramación de diligencias trascendentales, incongruencias manifiestas entre lo denunciado y las razones del archivo, interpretaciones jurídicas erróneas, interpretaciones discrepantes con el desarrollo jurisprudencial, entre otros (Informe Defensorial $\mathrm{N}^{\circ}$ 168, 2014).

La etapa de investigación preliminar es la base fundamental para el éxito del proceso, si bien es cierto, los elementos de convicción también pueden recabarse una vez formalizada la investigación preparatoria, pero para llegar a esta etapa se requiere la existencia de elementos de convicción que generen certeza o probabilidad suficiente de la comisión del delito. Por lo tanto, el fiscal debe ser un profesional competente e idóneo, con una formación jurídica sólida y que conozca el derecho penal, de modo que no se dispongan actos de investigación irrelevantes, de lo contrario se caerá en la cuenta de la ineficiencia, de lentitud de las investigaciones y consecuentemente en la impunidad.

Cabe acotar, que el fiscal como titular de la acción penal tiene la gran responsabilidad de poner en marcha el aparato estatal para perseguir el delito e indagar sobre los hechos materia de denuncia en afán de conocer o acercarse a la verdad. Por ello, el fiscal desde que recibe la denuncia o la noticia criminal debe ser diligente para ordenar de inmediato -de ser el caso- que actos de investigación se deben realizar; su negligencia, omisión, descuido, ineficiencia (indebida diligencia) tendrán como resultado el archivo de las denuncias en cualquier etapa del proceso, no porque los hechos no constituyen delito, sino porque durante el plazo de investigación no se recabaron suficientes elementos de convicción que generen información reveladora de la comisión del delito.

Resulta importante señalar, que la Corte Interamericana de Derechos Humanos (en adelante Corte IDH) ha establecido algunos principios generales de debida diligencia con la que deben actuar los fiscales para realizar investigaciones en casos de graves violaciones a Derechos Humanos:

1.- Oficiosidad: La investigación debe desarrollarse de oficio por parte de las autoridades competentes.

2.- Oportunidad: La investigación debe iniciarse de manera inmediata, ser llevada a cabo en un plazo razonable y ser propositiva.

3.- Competencia: La investigación debe ser realizada por profesionales competentes y empleando los procedimientos apropiados.

4.- Independencia e Imparcialidad: La autoridad encargada de realizar las investigaciones debe tener un accionar imparcial para no contaminar el proceso, debiendo buscar pruebas de cargo y descargo.

5.- Exhaustividad: La investigación debe agotar todos los medios para esclarecer la verdad de los hechos y proveer castigo a los responsables.

Los principios generales establecidos por la Corte IDH dan cierta luz sobre las obligaciones del fiscal, que más allá si aún no han sido desarrollados por la jurisprudencia nacional en casos de corrupción de funcionarios, resulta de vital importancia para que esta tenga éxito, pues su inobservancia ha conllevado al archivo preliminar de las denuncias.

El estudio de las carpetas fiscales archivadas en la presente investigación ha evidenciado un conjunto de problemas en las investigaciones fiscales realizadas, pues nos hemos encontrado con investigaciones deficientes, con insuficientes o inexistentes actos de investigación, pues se ha comprobado que los fiscales cuando reciben las denuncias solo se limitan a calificarla sin hacer ningún acto indagatorio que ayude a esclarecer los hechos; mientras que, en otros casos, se realiza aparentemente investigación, ya que la información recabada no aporta objetivamente al proceso, o son muy generales al momento de calificar los hechos en el tipo penal, concluyendo en ambos casos que los elementos de convicción ofrecidos y recabados no serían suficientes para iniciar investigación o formalizar la misma.

Tal situación resulta preocupante en la medida que no 
existe mecanismos de control a las investigaciones fiscales, teniendo en cuenta que el éxito de un proceso está en la calidad de la investigación desde su etapa inicial, esto es, que si se realiza una investigación deficiente lo más probable es que el caso fracase en cualquiera de sus etapas, ya sea por un archivo en investigación preliminar, sobreseimiento o absolución en etapa de juicio. Claro está, que estamos hablando de aquellos casos en los que al analizarlos tienen todos los requisitos para superar cualquier etapa del proceso, no obstante, fueron archivados al no haber recabado mayor información que lo ofrecido por el denunciante.

Esta realidad es contradictoria a lo establecido por el artículo $65^{\circ}$, inciso 1), del Código Procesal Penal, el cual indica que: "El Ministerio Público, en la investigación del delito, deberá obtener los elementos de convicción necesarios para la acreditación de los hechos delictivos, así como para identificar a los autores o participes en su comisión (...)". Asimismo, el artículo $14^{\circ}$ de la Ley Orgánica del Ministerio Público, que prescribe: "Sobre el Ministerio Público recae la carga de la prueba en las acciones civiles, penales y tutelares que ejercite (...)".

Como podemos advertir, el ordenamiento legal no establece que el denunciante tiene que investigar, recabar los elementos de convicción suficientes para luego realizar su denuncia; de ser así, el Fiscal cumpliría el papel de Juez y el denunciante el papel de Fiscal, Perito o Policía; por lo que quizás esta sea una causa del fracaso de las políticas criminales anticorrupción, no podría ser coincidencia que en los diferentes casos analizados se tengan similares resultados.

Así también, se ha identificado razonamientos jurídicos erróneos, materializado en el desconocimiento de las normas procesales y sustanciales, precedentes y jurisprudencias. Un claro ejemplo de ello es el Caso $\mathrm{N}^{\circ}$ 1206015500-2017-320 , en la que se pretendió equiparar una sanción administrativa a una sanción penal, situación que muy bien ha sido aclarada por el Tribunal Constitucional, “(...) no pueden equipararse las sanciones administrativas y las sanciones penales, pues ambas obedecen a fundamentos jurídicos distintos (...)" (Exp. N $\mathrm{N}^{\circ}$ 00361-2010-PA/TC, Fundamento 3).

Como podemos colegir, el caso materia de análisis data del año 2017, mientras que el criterio del Tribunal Constitucional data del año 2010; por lo que, salta a la vista que el Fiscal no tuvo el menor atino ni siquiera de revisar la normativa vigente, ya que resulta errado pretender en estos casos aplicar el principio non bis in ídem (principio de interdicción de la persecución penal múltiple); no obstante, fue citado por el Fiscal como causal de archivo.

También tenemos los casos $\mathrm{N}^{\circ} 1206015500-2016$ $82-0$ y $N^{\circ} 1206015500-2017-38-0$, en la que sin el menor cuidado la fiscalía verificó los hechos denunciados y la relacionó con otros procesos alegando que era de aplicarse el principio de interdicción de la persecución penal múltiple, cuando los hechos, los imputados e incluso el tipo penal no eran los mismos.

De los casos citados a modo de ejemplo, se advierte que los fiscales no actuaron diligentemente, entonces cobra mayor sustento la tesis de que un caso archivado indebidamente por negligencia del fiscal propicia la impunidad.

Finalmente, tenemos la falta de motivación presente en todos los casos analizados, pues se ha advertido que se denuncia por un hecho, se investiga a medias (por no decir ausencia de investigación), se realiza una calificación jurídica errónea de los hechos y no se motivan las decisiones.

El Tribunal Constitucional, respecto a la debida motivación ha precisado que, es una obligación constitucional que toda decisión de los poderes públicos esté respaldada en razones objetivas, es decir, que esté debidamente justificada, es consustancial al Estado democrático. El objeto de tal imposición es racionalizar la actuación del poder público, a efectos de que en su expresión diaria no impere la arbitrariedad ni el puro subjetivismo de quienes actúan desde cualesquiera de los estamentos del Estado (Sentencia recaída en el Exp. N ${ }^{\circ} 1744-$ 2005-PA/TC).

Por ejemplo, en el Caso N 1206015500-2016-58-0, se inicia la investigación y se califican los hechos por el delito de tráfico de influencias; sin embargo, se resuelve por colusión y peculado. Así también, en la mayoría de casos se menciona el artículo $334^{\circ}$, inciso 1) de la norma procesal, más no se precisa en que supuestos de archivo encuadra los hechos denunciados.

De otro lado, ante la puesta en evidencia de la indebida diligencia de la labor fiscal, debemos reflexionar ¿Por qué las políticas criminales contra la corrupción no son efectivas como espera la sociedad? ¿Por qué las denuncias por actos de corrupción no prosperan? ¿Por qué se utilizan los plazos máximos que la norma procesal prevé? ¿Por qué la sociedad tolera los actos de corrupción? Pues la sociedad espera más allá de qué se sancione o se absuelva al acusado (denunciado o imputado), que se conozca la verdad, y esto implica investigaciones eficientes en cada caso concreto, fiscales probos, diligentes e imparciales, que al margen de sus obligaciones tengan la voluntad de contribuir a la justicia. 
Una vez analizado los casos de la muestra de investigación, indudablemente la indebida diligencia de los fiscales (entendida como la falta de acuciosidad del Fiscal para realizar las investigaciones, calificar los hechos denunciados, sustentar sus disposiciones, entre otros) durante la investigación preliminar, tiene como consecuencia el archivo de los procesos; toda vez que resulta insustentable en la mayoría de casos formalizar investigación una vez culminado el plazo legal, ya que no se cuenta con elementos de convicción suficientes, no porque no los haya, sino porque no se recabaron a tiempo; asimismo, esta demás mencionar aquellos casos archivados por un razonamiento jurídico incorrecto.

\section{CONCLUSIONES}

1. Se ha determinado que la indebida diligencia de la labor fiscal en las investigaciones por los delitos de corrupción de funcionarios genera el archivo de los procesos, puesto que se ha logrado advertir investigaciones deficientes, calificaciones erróneas de los hechos denunciados, razonamientos jurídicos incorrectos y discrepantes con el desarrollo jurisprudencial, falta de motivación de las disposiciones, entre otros; lo cual viene generando un costo incalculable al sistema, de ahí que los esfuerzos del Estado para prevenir, sancionar y erradicar la corrupción hayan fracasado, quedando una incertidumbre de justicia o impunidad sobre los hechos denunciados.

2. El porcentaje de casos archivados por delitos de corrupción de funcionarios en la Fiscalía Provincial Especializada en Delitos de Corrupción de Funcionarios de Chachapoyas es totalmente alarmante, pues el $83 \%$ de denuncias son archivadas después de concluir la investigación preliminar, de esos archivos, solo el $45 \%$ son impugnados y elevados a la Fiscalía Superior Penal de Amazonas, de las cuales el 35\% son revocadas, es decir, de cada 10 procesos archivados e impugnados 4 son revocados.

3. No existe un protocolo ni normas de investigación específicas en delitos de corrupción de funcionarios que puedan servir de orientación y guía de actuación al personal fiscal de la Fiscalía Provincial Especializada en Delitos de Corrupción de Funcionarios de Chachapoyas para la conducción de sus investigaciones.

4. El archivo inadecuado de las investigaciones por delitos de corrupción de funcionarios en la Fiscalía Provincial Especializada en Delitos de Corrupción de Funcionarios de Chachapoyas, como consecuencia de la indebida diligencia de la labor fiscal, aumenta el riesgo de impunidad y disminuye la posibilidad de saber la verdad sobre los actos de corrupción denunciados, es decir, a más archivos, menos denuncias investigadas, menos sentencias, menos condenas y más impunidad.

\section{REFERENCIAS BIBLIOGRÁFICAS}

Arana, W. (2014). Manual de derecho procesal penal. $1^{\circ} \mathrm{ed}$. Lima - Perú: Gaceta Jurídica S.A.

Código Procesal Penal (2017). Lima: Jurista editores.

Constitución Política del Perú de 1993 (2017). Lima: Jurista editores.

Informe Defensorial No 168 (2014). El archivo fiscal de denuncias por peculado y colusión realizado en los distritos fiscales de Lima, Ancash, Ayacucho y Junín. Defensoría del Pueblo. $1^{\circ}$ ed. Lima-Perú. Recuperado de: https:/www.defensoria.gob.pe/modules/D ownloads/informes/defensoriales/InformeDefensorial-N-168.1.pdf

Rosas, J. (2009). Manual de derecho procesal penal. $1^{\circ}$ ed., Lima-Perú: Jurista editores.

San Martín, C. (2015). Derecho procesal penal: lecciones. $1^{\circ}$ ed. Lima - Perú: INPECCP y CENALES.

Sentencia del Tribunal Constitucional. Expediente $N^{\circ}$ 00361-2010-PA/TC. Disponible en: https://www.tc.gob.pe/jurisprudencia/201 0/00361-2010-AA.html

Sentencia del Tribunal Constitucional. Expediente $N^{\circ}$ 01744-2005-PA/TC. Disponible en: https://tc.gob.pe/jurisprudencia/2007/0174 4-2005-AA.pdf 